
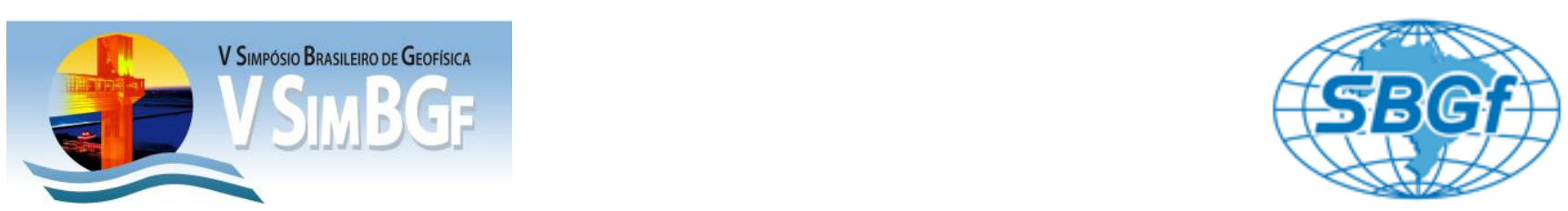

\title{
Determinação Epicentral Relativa de Sismos em Mara Rosa, GO, entre Outubro de 2010 a Março de 2011.
}

Thiago L. Jartas*, Marcelo S. Assumpção, Fabio Dias, Instituto de Astronomia, Geofísica e Ciências Atmosféricas.

Copyright 2012, SBGf - Sociedade Brasileira de Geofísica

Este texto foi preparado para a apresentação no V Simpósio Brasileiro de Geofísica, Salvador, 27 a 29 de novembro de 2012. Seu conteúdo foi revisado pelo Comitế Técnico do V SimBGf, mas não necessariamente representa a opinião da SBGf ou de seus associados. É proibida a reprodução total ou parcial deste material para seus associados. E proibida a reprodução total ou
propósitos comerciais sem prévia autorização da SBGf.

\section{Resumo}

Em 08/10/2010 na cidade de Mara Rosa, Góias, ocorreu um sismo de magnitude 5,0 Mb, sismo principal de uma série de sismo que estavam por vir naquela região. Esses sismos indicam uma reativação de uma falha geológica paralela ao Lineamento Transbrasiliano. O mecanismo de falhamento foi uma falha inversa de orientação SW-NE (Barros, L.V., et al 2012) com mergulho para NW. Foi feito um estudo sobre a determinação relativa de epicentros dos sismos ocorridos entre Outubro de 2010 a Março de 2011. O estudo demonstrou o não alinhamento dos epicentros com a direção de falhamento.

\section{Introdução}

Em 04/10/2010 ocorreu o primeiro sismo na cidade de Mara Rosa com magnitude 3,6, esse foi o sismo precursor de uma série de sismo que se estendeu desde Outubro de 2010 a Março de 2011, após quatro dias foi registrado um sismo de $5,0 \mathrm{Mb}$ considerado o sismo principal dessa série, o de maior magnitude, e apenas oito minutos depois ocorreu outro sismo de magnitude 4,6 , sendo esse considerado o sismo secundário. Desde 1962 já havia registros de sismos nessa região, com intensidades até $\mathrm{V}, \mathrm{A}$ atividade sísmica dessa região está distribuída em uma direção NE-SW, que indica a reativação de uma falha do Lineamento Transbrasiliano. Desta série de sismos foram escolhidos os que apresentaram registros de ondas a distâncias regionais para que fosse feito a correlação entre eventos de magnitudes próximas, e determinar a posição relativa entre eventos. As ondas correlacionadas foram as ondas superficiais Rayleigh com trem de ondas com período próximo de 1 s. O sismo que ocorreu em 08/10/2010 e magnitude de 5,0 Mb foi fixado como ponto de referência, com suas coordenadas calculadas pelo ISC.

\section{Metodologia/ Problema Investigado}

Foram utilizadas diversas estações espalhadas pela América do Sul, que registraram os sismos ocorridos entre Outubro de 2010 a Março de 2011. Os dados foram filtrados (1-2 Hz) e em seguida foi feita uma correlação das ondas Rayleigh e $\mathrm{Lg}$, entre o sismo principal e as réplicas estudadas, gerando uma diferença de tempo para cada estação. Essa diferença de tempo (Figura 1) é causada pela diferença de distância entre os epicentros e as estações. Para encontrar a distância entre os

epicentros foi levado em consideração o azimute da estação em relação ao epicentro do sismo principal. Variando o azimute podemos gerar uma curva teórica que melhor se adequaria a esse padrão de variação, de acordo com a fórmula abaixo.

$$
T_{2}-T_{1}=\frac{-d_{0} \cos \left(A_{g}-A_{g}\right)}{V_{a p}}
$$

Onde $T_{2}$ é o tempo de percurso da réplica, $T_{1}$ é o tempo de percurso do sismo principal, d é a distância entre os epicentros, $A_{g}$ é o azimute da estação em relação ao epicentro, $A_{\theta}$ é o azimute do evento em relação ao epicentro do sismo de referência e $V_{a p}$ é a velocidade aparente, próximo de $3,0 \mathrm{~km} / \mathrm{s}$ para ondas de superfície.
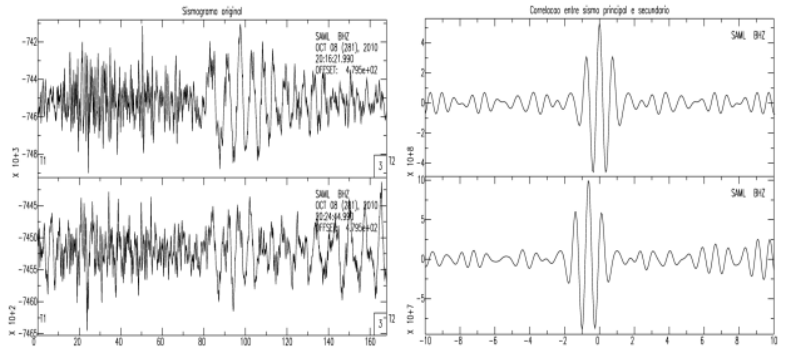

Figura 1: Sismograma sem filtro e correlação a esquerda, e sismograma filtrado e correlacionado a direita.

Pela equação da curva teórica foi possível encontrar a distancia entre um par de eventos correlacionados e a que direção este evento se encontra em relação ao evento fixado como referência.

\section{Resultados}

Com as correlações feitas foi feito o melhor ajuste em uma curva teórica para cada par de eventos estudados. O gráfico abaixo representa os resultados das correlações entre o sismo principal e o sismo secundário, esquerda, e as correlações entre o sismo principal e o precursor.

Para o ajuste dessa curva teórica foi utilizado uma velocidade aparente de $3,0 \mathrm{~km} / \mathrm{s}$, e uma distância de 0,5 $\mathrm{km}$ em uma direção de $15^{\circ}$ em relação ao azimute. 


\section{T2-T1 (s) x Azimute, As ( $\left.{ }^{\circ}\right)$}

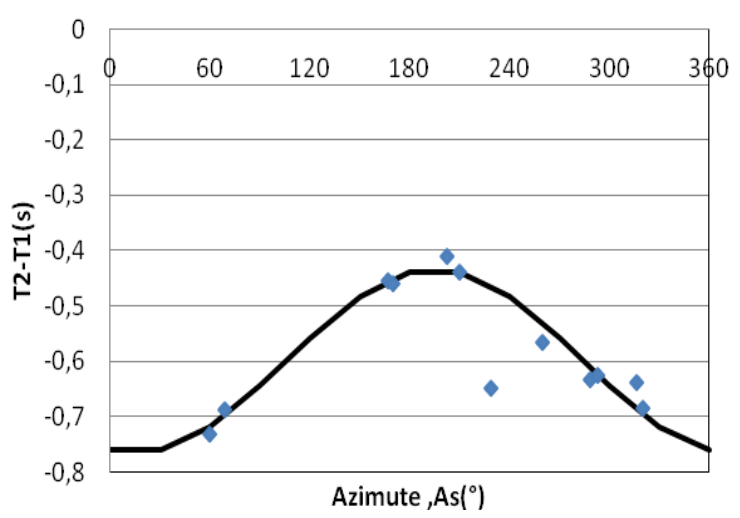

Figura 2: Correlação entre sismo principal e secundário.
$\mathrm{PIBIC/CNPq}$ agencia financiadora

\section{Referências}

Tapley, C. \& Tull, E. SAC - Seismic Analysis Code: Users Manual. University of California. 1991. 423p

Barros, L.V., et al., 2012. THE MARA ROSA, GOIÁS STATE, BRAZIL, RECENT SEISMICITY AND ITS RELATIONSHIP WITH THE TRANSBRASILIANO LINEAMENT. Latin American Seismology Symposium, Lima, Peru, September 2012, extended abstr.

\section{Discussão e Conclusões}

Com os epicentros calculados, utilizando as curvas teóricas, podemos gerar um mapa com as posições relativas entre eles que estão representadas na Figura 3.

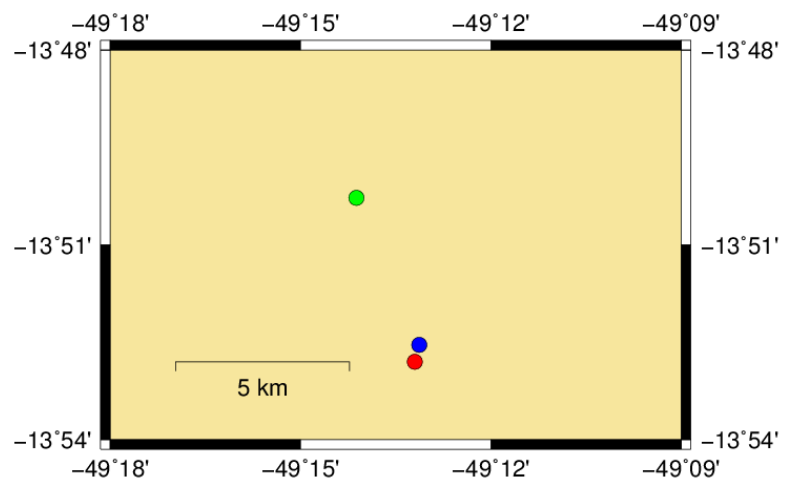

Figura 3: Posições relativas dos epicentros, em vermelho sismo principal, azul sismo secundário e verde sismo precursor.

De acordo com a Figura 3 os epicentros calculados não estão alinhados com a direção esperada, SW-NE, Isso se deve às diferentes profundidades dos eventos. O sismo precursor deve ter profundidade maior que o evento principal

Esse método de determinação relativa é simples de ser feito, mas requer um grande número de estações, pois alguns eventos de menor magnitude não são bem registrados em estações distantes.

No entanto a relação com o mecanismo focal de falhamento depende das profundidades dos sismos que não podem ser calculadas por este método. O método deve ser mais eficiente em falhas verticais transcorrentes.

\section{Agradecimentos}

\section{Grupo de Sismologia IAG-USP}

Jose Roberto Barbosa 